\title{
The real implications of Dolly
}

\section{Jonathan J. MacQuitty}

Over the past weeks, intense publicity surrounding the "cloned" sheep, Dolly, has focused, almost exclusively, on the implications for human cloning and the ethical dilemmas this poses. Concerned at the prospect of human clones, US Senator Christopher Bond (Rep., MI) and Representative Vernon Ehlers (Rep., MI) have already introduced legislation to ban human cloning research. Others feel that such a ban could be damaging: At a recent hearing of the House Science Technology Subcommittee of the Senate, Senator Tom Hawkins (Dem.) from Iowa said that he looks forward to human cloning and that we cannot put a "stop" to this type of work. Earlier, the UK Ministry of Agriculture had canceled some of the funding for Ian Wilmut at the Roslin Institute (Edinburgh, UK) where the work was carried outalthough this now appears to be more of a ploy to attract commercial sponsorship than a response to any ethical concerns raised about the research.

Lost in these discussions, I think, have been the real implications of this work, both on the scientific side and more particularly on the commercial side. It is clear looking at the science that the research leading to Dolly was a major advance. It is also apparent that many interesting questions remain to be answered. Rather like the sound-barrier breaking flight of Chuck Yeager, Ian Wilmut and his group have broken the barrier in cell development by resetting the "clock" of an adult animal cell. But can this technique be applied to any adult cell or is the process restricted to certain stem cells in the mammary gland or elsewhere? Is the technique restricted in terms of species? What kind of developmental problems might occur with greater frequency with cloned animals? These are questions regarding cell development for which we do not currently have answers.

Then there is the issue of what impact this technique will have on the generation of transgenic animals. There has been considerable speculation in the press on this point. But from a scientific standpoint, the practical applications of this technique remain uncertain in the near term. It is not yet clear that nuclei from adult cell lines that have been transfected with new DNA will be able to

Jonathan J. MacQuitty is chief executive officer of GenPharm International, 855 California Avenue, Suite C, Palo Alto, CA 94304 (jmacquitty@genpharm.com). withstand the process of nuclear transfer. Certainly, in vitro manipulation of embryonic stem (ES) cells affects their ability to form viable chimeric embryos. This aside, there is reason for optimism that effective manipulative techniques for cloning could be developed over time to extend the breadth of the work-much in the same way that techniques for ES cells have been refined over recent years.

The cloning breakthrough did not happen overnight. It is part of a long continuum of research into cell development, some of which has come from Wilmut and his group. Earlier last year, they reported the successful transplantation of nuclei from sheep blastocysts-early stage embryos-into enucleated eggs. Previous research by other groups on nuclear transfer and cloning in other mammals (e.g., cows) has also contributed. Indeed, the cloning of Dolly has precipitated a flow of reports on cloning and related research from a host of other groups. Invariably, the media "forgets" this context, a factor that can lead to some rather inaccurate predictions for this work.

The commercial implications of Dolly have been handled with rather more hand waving than usual. One of the press releases accompanying the announcement of Dolly mentions how transgenic animals will now be made from genetically modified cell lines. This, of course, assumes that the nuclei from such cell lines could be successfully transferred to yield viable embryos. But if, in the near term, we focus on cloning as a technique to simply expand a herd of transgenic animals such as sheep, its commercial value appears much more limited. It is true that nearly identical animals can be produced from cloning and that this could be helpful in certain projects; for example, in developing animals for producing transgenic organs. But for production of proteins in the milk of transgenic animals, cloned animals are unlikely to be critically important.

Similarly, the use of this cloning technique as a substitute for conventional breeding with nontransgenic animals will only pay off when having "nearly" identical animals is necessary. (As Harold Varmus, the Director of the US National Institutes of Health [Bethesda, $\mathrm{MD}$ ], pointed out in the Senate hearings, these cloned animals will not have the same mitochondrial DNA and may have other minor genetic differences.) For most livestock applications, the cost and loss of genetic diversity is likely to preclude cloning as a routine commercial practice. However, one area where cloning might be especially valuable is in the breeding of endangered species. The ability to clone multiple individuals from a single founder could help preserve species such as pandas that have been difficult to breed in captivity.

At some point, it may be possible to apply homologous recombination to adult animal cells in culture followed by nuclear transfer to generate cloned animals containing gene "knockouts." But this is far off in the future. For now, the real implications of Dolly for transgenic animal development are likely to be limited.

When discussing human cloning, the implications cited in the press become even more fanciful. In one article, Wilmut was reported to have told the UK Parliamentary Select Committee on Science and Technology that human clones could be obtained within one to two years-no mention was made of his qualifier that such a feat would require concerted effort and limitless funding. In contrast, a report on his testimony to a Senate panel said that Wilmut felt his technique was not ready for human cloning experiments. Certainly, from a scientific standpoint, the cell development process in early stage mammalian embryos varies substantially between sheep and humans. There may be significantly more room for maneuver with sheep nuclei and sheep cells in terms of reprogramming than with their human counterparts.

Absent from this coverage, in large part, has been any reference to the growing developments that are taking place in cell culturing techniques and in our ability to manipulate a cell's activity. Rather than cloning humans to provide "spare parts"an odious thought-why not reprogram human cells so that they can grow and develop in vitro into organ or organ-like masses? If more work was directed to this aspect of cell development, we might move more rapidly toward solving the critical shortage of organs for transplantation purposes.

This seems to me the most important implication of Dolly and her future clones. If we could build upon our growing capability to manipulate cells and to modify the molecular and environmental factors that govern their activity, we might be able to understand and control cells in vitro to the point where cellular therapies could become powerful clinical tools for a very wide range of conditions. If, by chance, Dolly's announcement brings an influx of money and talent into these aspects of cellular and developmental biology, then all this hyperbole will have been worthwhile. III 